\title{
Physiological and transcriptomic responses of Mikania micrantha stem to shading yield novel insights into its invasiveness
}

\author{
Zhaoyang Jiang ${ }^{1}$, Yaping Zheng ${ }^{1}$, Minling Cai ${ }^{1}$, Changlian Peng ${ }^{1}$, Yutao Wang ${ }^{1}$, and \\ Weihua $\mathrm{LI}^{1}$ \\ ${ }^{1}$ South China Normal University
}

August 5, 2020

\begin{abstract}
The rapid stem elongation of the invasive weed Mikania micrantha in the forest understory is of vital significance for its successful invasion. To understand the physiological and molecular mechanisms for this process, here we comparatively investigated the physiological characteristics and transcriptome patterns of M. micrantha stem under low light (30\%) and full light (100\%) conditions. The results showed that $M$. micrantha stem had photosynthetic capacity, which was highly plastic to light intensities, constituting of an indispensable part of the plastic response of $M$. micrantha to shading. M. micrantha had longer internodes, epidermal cells, and consequently longer stems under low light than full light conditions, which could be attributed to the reduced photoprotective substances (flavonoid and anthocyanin) and increased synthesis of phytohormones (gibberellin, GA and Auxin) as observed under shading treatment. The transcriptome sequencing and qPCR verified the results from physiological investigation, and showed that under low light condition the expression levels of genes involving in photosynthesis (e.g. $M m P s a A$, $M m P s b O 1$ and $M m F d 3)$ were generally down-regulated in comparison to full light condition, so were the genes related to the photoprotective substances synthesis (e.g. MmCHS, and MmF3H1) and the negative regulators of phytohormone (e.g. $M m A U X 1, M m R R 1$ and $M m G A I)$. It was concluded that the regulation of phytohormones and photoprotective substances are the important material basis for the rapid elongation of $M$. micrantha stems with high plasticity, which really matters to the vine to have high invasiveness in the forest understory.
\end{abstract}

\section{Hosted file}

the ms of Mikania transcriptome.doc available at https://authorea.com/users/348827/articles/ 474027-physiological-and-transcriptomic-responses-of-mikania-micrantha-stem-to-shadingyield-novel-insights-into-its-invasiveness

\section{Hosted file}

Fig.1.doc available at https://authorea.com/users/348827/articles/474027-physiological-andtranscriptomic-responses-of-mikania-micrantha-stem-to-shading-yield-novel-insights-intoits-invasiveness

\section{Hosted file}

Fig.2.doc available at https://authorea.com/users/348827/articles/474027-physiological-andtranscriptomic-responses-of-mikania-micrantha-stem-to-shading-yield-novel-insights-intoits-invasiveness

\section{Hosted file}

Fig.3.doc available at https://authorea.com/users/348827/articles/474027-physiological-andtranscriptomic-responses-of-mikania-micrantha-stem-to-shading-yield-novel-insights-into- 
its-invasiveness

\section{Hosted file}

Fig.4.doc available at https://authorea.com/users/348827/articles/474027-physiological-andtranscriptomic-responses-of-mikania-micrantha-stem-to-shading-yield-novel-insights-intoits-invasiveness

\section{Hosted file}

Fig.5.doc available at https://authorea.com/users/348827/articles/474027-physiological-andtranscriptomic-responses-of-mikania-micrantha-stem-to-shading-yield-novel-insights-intoits-invasiveness 